\title{
Honey-Bee Localization Using an Energy Harvesting Device and Power Based Angle of Arrival Estimation
}

Shearwood, Jake; Hung, Daisy Man Yuen; Cross, Paul; Preston, Shaun; Palego, Cristiano

\section{IEEE/MTT-S International Microwave Symposium - IMS}

\section{DOI:}

10.1109/MWSYM.2018.8439173

Published: 01/01/2018

Peer reviewed version

Cyswllt i'r cyhoeddiad / Link to publication

Dyfyniad o'r fersiwn a gyhoeddwyd / Citation for published version (APA):

Shearwood, J., Hung, D. M. Y., Cross, P., Preston, S., \& Palego, C. (2018). Honey-Bee Localization Using an Energy Harvesting Device and Power Based Angle of Arrival Estimation: 2018 IEEE/MTT-S International Microwave Symposium - IMS. IEEE/MTT-S International Microwave Symposium - IMS, 957-960. https://doi.org/10.1109/MWSYM.2018.8439173

\footnotetext{
Hawliau Cyffredinol / General rights

Copyright and moral rights for the publications made accessible in the public portal are retained by the authors and/or other copyright owners and it is a condition of accessing publications that users recognise and abide by the legal requirements associated with these rights.

- Users may download and print one copy of any publication from the public portal for the purpose of private study or research.

- You may not further distribute the material or use it for any profit-making activity or commercial gain

- You may freely distribute the URL identifying the publication in the public portal ?
}

Take down policy

If you believe that this document breaches copyright please contact us providing details, and we will remove access to the work immediately and investigate your claim. 


\title{
Honey-Bee Localization Using an Energy Harvesting Device and Power Based Angle of Arrival Estimation
}

\author{
Jake Shearwood $^{1}$, Daisy Man Yuen Hung ${ }^{1}$, Paul Cross ${ }^{2}$, Shaun Preston ${ }^{1}$ and Cristiano Palego ${ }^{1}$ \\ ${ }^{1}$ School of Electronic Engineering, Bangor University \\ ${ }^{2}$ School of the Environment, Natural Resources and Geography, Bangor University \\ Email:*eu91b@bangor.ac.uk
}

\begin{abstract}
A novel approach for real-time monitoring of honey-bees across their natural habitat is presented herein. We present a wearable device which scavenges energy from the bee's mechanical vibrations to power the transmission of location data while ensuring minimal physical hindrance. The geo-physical location of honey-bees is determined by implementing a compact and low weight scanning system that can be used with a stationary receiver or coupled to a movable receiver for tracking across the entire foraging range. This is achieved through the combination and synchronization of a RF detector, steerable microstrip array and a microcontroller to estimate angle of arrival using received signal strength indicator (RSSI). The present approach addresses the fundamental limitations of current telemetry systems in terms of cost and adverse size/weight impact over the bee foraging behavior.

Index Terms - Energy harvesting, piezoelectric effect, localization, Received signal strength indicator, Direction-of-arrival estimation
\end{abstract}

\section{INTRODUCTION}

The large-scale decline of honey-bees (Apis mellifera L.) has ignited strong interest into understanding the spatial use and movement of the bees in their natural environment [1]. Radio transmitters for tracking have been used for over 50 years providing insights into animal behavior. Multiple limitations have been outlined, which restricts applying the technology to smaller-bodied insects, with the lightest commercially available tags available weighing $>0.2 \mathrm{~g}$ [2-3], whilst the average weight of a honey-bee is $0.11 \mathrm{~g}$. A novel solution is proposed whereby the need for a battery is obviated by harvesting the bees' own energy enabling the use of a much lighter device [4]. The battery is replaced by a piezoelectric energy harvester capable of converting mechanical energy from the bee's thorax into electrical energy. The energy harvester is co-designed with a power management unit and transmitting antenna.

Passive tags have also been utilized to track honey-bees using both harmonic radar and RFID approaches, however, even after recent advances [5], systems are unable to provide flightbehavior information for a honey-bee across its entire foraging range [1]. Such limitation can be overcome by implementing a radio telemetric approach. We have developed a system which consists of three main components: 1 - An active transmitter (vibration powered) that will be attached to a honey bee; 2. An antenna system; 3 . A radio receiver. The role of the active transmitter is to scavenge the energy produced from honey-bee flight to transmit an RF beacon at $5.8 \mathrm{GHz}$, in which an antenna system and radio receiver will locate the beacon. The current system supports a stationary receiver capable of integration into a smart greenhouse or polytunnel to monitor movement, whilst also being capable of coupling to a drone for long range tracking.

\section{ENERGY HARVESTING FROM BEE FLIGHT}

\section{A. The need for device miniaturization}

Piezoelectric energy harvesting has demonstrated potential to convert an insect's mechanical vibrations into constant electrical energy, facilitating a more aggressive weight reduction and device miniaturization approach due to its compact nature. Honey-bee wing beats vary between $208 \mathrm{~Hz}-277 \mathrm{~Hz}$ during flight, which depends on physical and environmental factors [6]. We measured the change in magnitude and flapping frequency due to physical constraints, which is depicted in Figure 1 . Bees can carry loads up to $110 \%$ of their body weight. However, no study has investigated the energy costs to bees caused by the additional weight of transmitters [1].

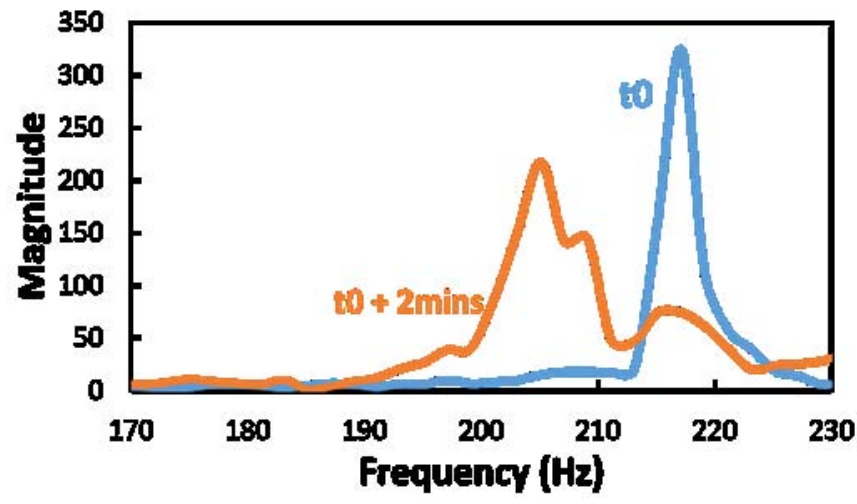

Fig.1. Spectrum of the piezoelectric beam output signal outlining both frequency and amplitude changes due to physical tiredness of the honey-bee.

For a preliminary dimensioning of the system a piezoelectric beam weighing approximately $120 \%$ of a honey-bees' own weight was placed on the thorax as shown in Figure 2. By taking the FFT of the output from the piezoelectric beam during 
honey bee flight, the change in frequency due to physical constraints over a small period of time has been observed. Since the magnitude of the signal is related to the force produced by the thorax [6], the results in Figure 1 outline the need to pursue device miniaturization for minimal energy expenditure during carrying the device. The data collected from this experiment allows to optimise the reduced size beam which is expected to weigh $\sim 40 \%$ of the bee.

\section{B. Model optimization for power generation}

To enable device miniaturization while maximizing the achievable power output we developed an analytical model capable of accurately predicting power generation from the piezoelectric beam. During flight, the bee's thorax provides an external force to directly excite the tip of the beam. This provides continuous deflection whilst eliminating the need to match actuation frequency and resonance. The current piezoelectric device consists of two $130 \mu \mathrm{m}$ thick PZT-5A layers separated by a $130 \mu \mathrm{m}$ brass shim (length $31.8 \mathrm{~mm}$, width $1 \mathrm{~mm}$ ). The power generated from the direct force can be estimated by [6]:

$$
P=\frac{V^{2}}{R_{L O A D}}=\frac{9}{64} \cdot \frac{E_{p} d_{31}^{2}}{\varepsilon} \cdot \omega_{A C T} \cdot K_{S P R I N G} \cdot Z_{P E A K}^{2}
$$

Where $E_{p}$ is the Young's modulus, $d_{31}$ is the piezoelectric strain coefficient, $\varepsilon$ is the dielectric constant, $\omega_{A C T}$ is the actuation frequency while $K_{S P R I N G}$ is the stiffness of the beam and $Z_{P E A K}$ is the maximum deflection of the beam. To test the power generation of the current larger scale device $(\sim 3: 1)$ the following protocol was established:

1) Immobilization of the honey-bee by controlled hypothermia at $-10^{\circ}$ for two minutes.

2) Attachment of a $0.5 \mathrm{~mm}$ diameter tungsten probe to the thorax of the bee using Dymax-208-CTH-F to tether the bee.

3) Placement of the tip of the piezoelectric beam against the bees' thorax and measure output across the optimal load resistor.

Using COMSOL Multiphysics [7], a finite elements model replicating the experiment in Figure 2 was created in order to predict the power generated. Previous studies have measured the force produced from the thorax during tethered flight [8]. Using stationary analysis a value for $Z_{P E A K}$ was found and applied to Equation 1, which predicted a $3.66 \mu \mathrm{W}$ output. Figure 2(b) highlights the experimental results showing $3.6 \mu \mathrm{W}$ generated across an optimal load. The results suggest that device optimization can be performed through simulation to maximize the power output of the energy harvester.

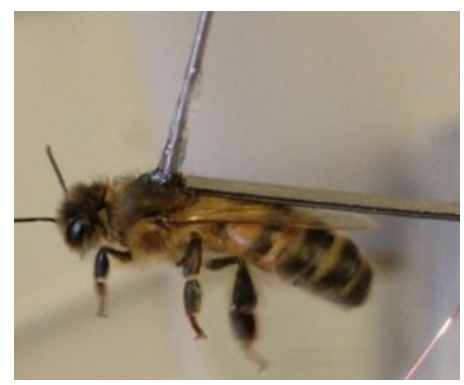

(a)

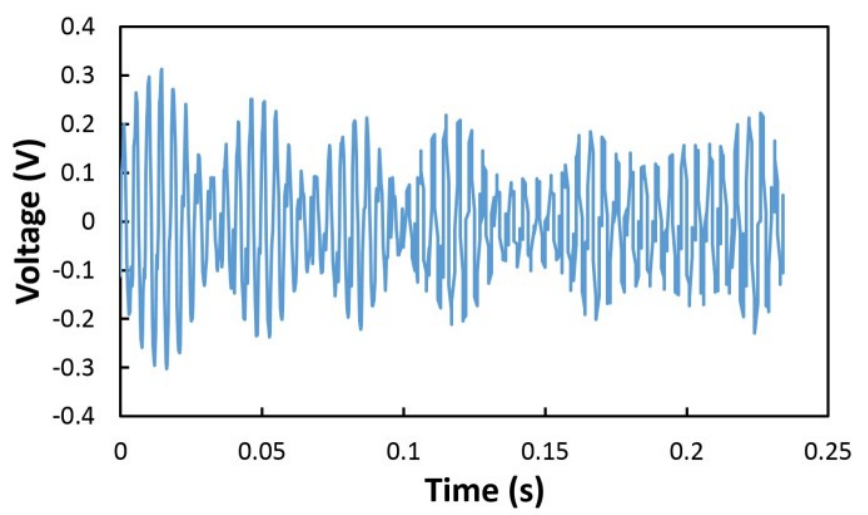

(b)

Fig.2. Experimental procedure for harvesting energy from tethered honeybee flight. (a) Tethered bee with tip of piezoelectric beam resting against the thorax (b) Measured output voltage across optimum load

\section{PORTABLE LOCATION SYSTEM BASED ON ANGLE OF ARRIVAL TECHNIQUE}

\section{A. Portable system overview}

The localization system design is based on the use of the RSSI to obtain angle of arrival estimates [9]. Current commercially available systems, [3] are based on the same approach, however, operate at much lower frequencies impairing integration of the technology to drones, as well as providing lengthy periods of time for positional updates. As the objective is to integrate the receiver system to a moveable drone we require a resource constraint approach achieving localization with a lightweight and compact solution. We designed and manufactured a directional patch array operating at $5.8 \mathrm{GHz}$ capable of being attached to a stepper motor to perform mechanical scanning. By connecting the array to a logarithmic detector a voltage level can be obtained corresponding to the received power. As input power is increased, successive amplifiers move into saturation one by one creating an accurate approximation of the logarithmic function. A microcontroller is responsible for scanning the antenna whilst simultaneously recording and processing the received signal strength. The microcontroller is connected to a power management unit enabling the entire system to be operated using a single $7.2 \mathrm{~V} \mathrm{LiPO}$ battery with a $45 \mathrm{mi}-$ nute operation time and is capable of operating on a $20 \mathrm{~cm} \mathrm{x}$ $17 \mathrm{~cm}$ platform with a total weight $<1 \mathrm{Kg}$. 


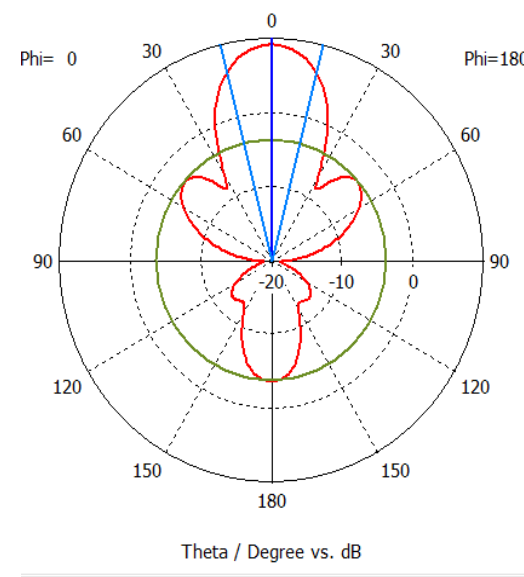

(a)

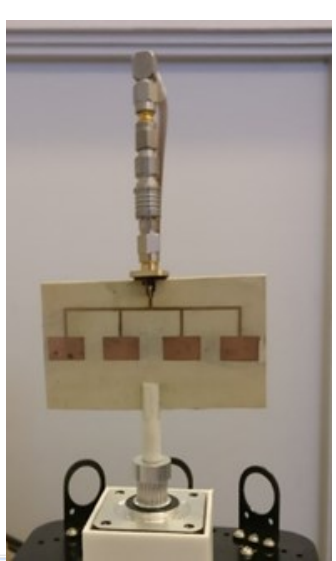

(b)
Fig.3. (a) $5.8 \mathrm{GHz}$ radiation pattern of the patch array obtained using CST microwave studio. (b) Antenna and mechanical scanning system used to obtain angle of arrival

\section{B. Obtaining angle of arrival and distance estimates}

The angle of arrival can be obtained by manually scanning a directional antenna, which is used in radio telemetry systems [10]. Such an approach has an element of user error which, is eliminated by replacing the user with a mechanical scanning system. As proof of the principle we used a stepper motor to perform scanning, controlling the system with a microcontroller to create an autonomous location system. The system can be modified to peruse further weight and size reduction by replacing the stepper motor with the development of an electronic steering system.

A directional patch antenna array is incorporated into the system to scan all angles of interest. The system is capable of constructing a curve of the received signal strength as a function of antenna rotation in real-time.

We obtained a curve linking the received signal strength as a function of the angle difference between transmitter and receiver (Figure 4). With the addition of multiple receivers and the knowledge of the position of each receiver, the distance of the target can also be obtained.

Estimation of the distance between transmitter and receiver cannot be achieved with a single receiver. The receiver is capable of identifying the angle of arrival using RSSI, however when multiple readings are taken the received signal strength varies due to error with the RF detector readings. Figure 5 shows the variation in signal strength for multiple readings taken at the same location, highlighting the importance of incorporating multiple receivers with known locations to achieve accurate distance measurements

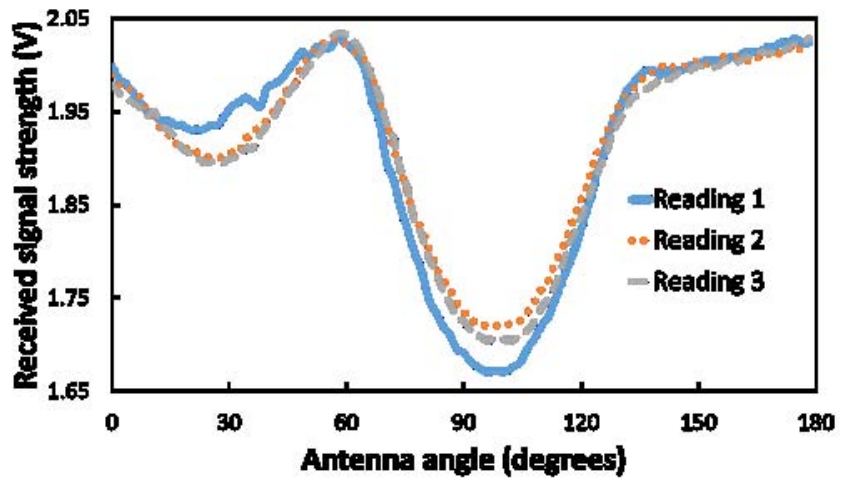

Fig.4. Fluctuation in RSSI for repeated measurements at same angle and distance.

\section{System localization accuracy indoors}

The system was tested in a laboratory environment. The initial proof of concept was carried out at $0 \mathrm{dBm}$, a higher power output than expected from transmitter design. Further optimization at both the receiver and transmitter side in the forms of geometrical antenna changes, enhancement in harvested power and the inclusion of a low noise amplifier for a highly sensitive receiver [11] which will allow the system to operate at lower power levels. The antenna system scans through X degrees with a step of $1.8^{\circ}$ every $5 \mathrm{~ms}$. This corresponded to a total scan time of 0.5 seconds. During each scan position, 50 measurements of the received signal strength were taken so that an average reading could be obtained. To test the accuracy of the system, a random path was taken in which a transmitter moved quickly around a laboratory. A curve displaying the RSSI vs angle allowed the bearing estimate. Figure 5 depicts the differences between actual and measured bearing, outlining the accuracy of the system.

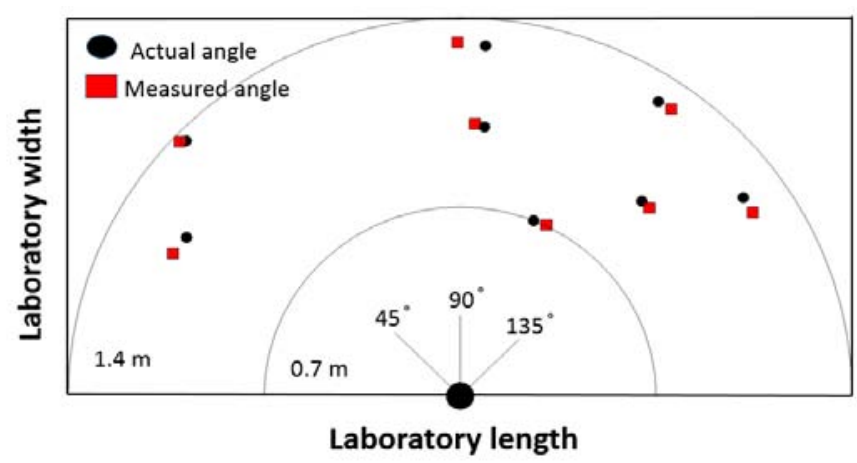

Fig.5. Actual angle vs measured angle depicting the accuracy of the system for angle estimation between transmitter and receiver.

Similar work have proposing a system of rotating omnidirectional antennas to determine the angle of arrival have demonstrated an accuracy of $6^{\circ}$ [12]. Angle of arrival has also been 
estimated using a space and frequency division multiple access (SF-DMA) approach [13] achieving a mean error in the azimuthal direction of $4.9^{\circ}$. Our system has also yielded maximum error on the angle of arrival of $+/-5^{\circ}$ with a compact transmitter and receiver antenna configuration.

\section{CONCLUSION}

A low-cost, portable location system based on angle of arrival using RSSI is presented. The system consists of a microcontroller, RF detector and patch array mounted to a stepper motor operating in the ISM band at $5.8 \mathrm{GHz}$. The system is capable of processing and displaying localization data in real time while constantly monitoring the movements of the wearable tag. Since the system is portable it can be mounted on a drone to track honey bees' across their entire foraging range. Experimental results have demonstrated an accuracy of approximately $5^{\circ}$ in 0.5 seconds.

\section{ACKNOWLEDGMENT}

The authors gratefully acknowledge the financial support provided by the Knowledge Economy Skills Scholarships (KESS 2, Ref: BUK226).

\section{REFERENCES}

[1] W. Daniel Kissling, D. Pattemore and M. Hagen, "Challenges and prospects in the telemetry of insects", Biological Reviews, vol. 89, (3), p. 511-30, 2013
[2] B. Naef-Daenzer, "Miniaturization (0.2 g) and evaluation of attachment techniques of telemetry transmitters", Journal of Experimental Biology, vol. 208, no. 21, pp. 4063-4068, 2005.

[3] I. Advanced Telemetry Systems, "Series | Advanced Telemetry Systems", Atstrack.com, 2017

[4] J. Shearwood, D. Man Yuen Hung, P. Cross and C. Palego, "Energy harvesting powered devices for honey bee health monitoring", in International Microwave Workshop Series on Advanced Materials and Processes, Pavia, 2017.

[5] D. Milanesio, M. Saccani, R. Maggiora, D. Laurino and M. Porporato, "Design of an harmonic radar for the tracking of the Asian yellow-legged hornet", Ecology and Evolution, vol. 6, no. 7, pp. 2170-2178, 2016.

[6] E. Aktakka, H. Kim and K. Najafi, "Energy scavenging from insect flight", Journal of Micromechanics and Microengineering, vol. 21, (9), p. 095016, 2011.

[7] Comsol Multiphysics 5.2. Comsol, 2017

[8] J. Coelho, "The Effect of Thorax Temperature on Force Production during Tethered Flight in Honeybee (Apis mellifera) Drones, Workers, and Queens", Physiological Zoology, vol. 64, no. 3, pp. 823-835, 1991.

[9] B. Hood and P. Barooah, "Estimating DoA From Radio-Frequency RSSI Measurements Using an Actuated Reflector", IEEE Sensors Journal, vol. 11, no. 2, pp. 413-417, 2011

[10] L. D. Mech and S. M. Barber, "A critique of wildlife radio-tracking and its use in national parks: a report to the National Park Service," U.S. Geological Survey, Northern Prairie Wildlife Research Center. Jamestown, N.D., 2002

[11] Analog Devices," HMC602LP4 / 602LP4E 70 dB, Logarithmic detector / controller, 1-8000 MHz," http://www.analog.com/media/en/technicaldocumentation/data-sheets/hmc602.pdf, 2017, v03.0209.

[12] M. Malajner, P. Planinsic and D. Gleich, "Angle of Arrival Estimation Using RSSI and Omnidirectional Rotatable Antennas", IEEE Sensors Journal, vol. 12, no. 6, pp. 1950-1957, 2012.

[13] S. Maddio, A. Cidronali, M. Passafiume, G. Collodi, M. Lucarelli and S. Maurri, "Multipath Robust Azimuthal Direction of Arrival Estimation in Dual-Band 2.45-5.2 GHz Networks", IEEE Transactions on Microwave Theory and Techniques, vol. 65, no. 11, pp. 4438-4449, 2017. 